\title{
Application of Problematic Technology Roadmapping in Less Developed Regions of Slovakia
}

\author{
Marek Jemala $^{1 *}$, Karol Hatiar ${ }^{2}$, Alena Pauliková ${ }^{2}$ \\ ${ }^{1}$ Doc. Dr. Marek Jemala, Institute of Civil Society, University of Ss. Cyril and Methodius in Trnava \\ ${ }^{2}$ Doc. Dr. Karol Hatiar and Doc. Dr. Alena Pauliková, Institute of Industrial Engineering and Management, \\ Faculty of Materials Science and Technology, STU in Trnava
}

\begin{abstract}
This economic research was based on the literary analysis, various empirical studies and statistical vs. qualitative research in 500 problematic companies mainly in the East of Slovakia. Businesses received about 100 questions about technology innovation management, innovation support, strategic planning, Roadmapping, Risk management, etc. These statistical results were completed by the expert consultations in 2018-2019. Based on the research results, it can be concluded that these problematic companies are mainly micro-companies with up to 10 employees (mostly Ltd.), mainly in the construction, engineering, automotive, rubber, and plastic industries. These companies are dominated by piece and series production. The use of technology RM processes was minimal and only applied in larger companies (TR $\geq 500000 €$ ). These roadmapping processes have been greatly simplified and unsystematic, mainly based on the requirements of the concern, business owners or top managers.
\end{abstract}

Keywords: Problematic technology roadmapping, Crisis management, complex technology innovation, corporate foresight. 


\title{
2nd International Conference on Applied Research in ENGINEERING SCIENCE \& TECHNOLOGY
}

\author{
Budapest, Hungary
}

\section{Introduction}

Business roadmapping approaches have been more visible in the U.S. practice of Strategic management. Under the leadership of Robert Galvin, Motorola initiated a strategic, wide process with a stated purpose of encouraging business managers to properly focus on their technological future as well as provide them with a vehicle to organize their forecasting and planning processes. The approach was introduced to help balance between long- and shortrange issues, strategic and operational matters - mainly with technology innovation - and other processes in a company (Duckles \& Coyle, 2005). Motorola found that the establishment of this pervasive "culture" of participatory visual planning enabled the company to find solutions that better communicate the vision and strategic goals of management, stimulate investigations and control the progress.

As such, strategic participatory planning has gained potential as a key management tool for an organization to integrate innovation and a business strategy. Further, based on a literature study, the question of maintaining a roadmapping plan alive has been identified as a key challenge in this area. Therefore, in order to address this challenge, the functionality and effective implementation of roadmapping are highlighted as potential areas for future research (Vatananan \& Gerdsri, 2012). Corporate foresight and its method: Technology roadmapping have become a riddle of information correctness and one of the main tools for a strategic innovation decision making. A key piece of knowledge for innovation managers in industrial enterprises is that to achieve competitive timing or synergy in both industry and market, the roadmap should provide important strategic means to achieve these goals, and dialogue and stimulation are critical in implementing an organization's roadmap. (Simonse et al., 2014) However, many times, a roadmap is only a "product" of strategic planning, but not a functional process of Strategic management. Roadmapping, in simplicity, must be a kind of a learning process for a group of stakeholders, which discover trends, gaps and new variant directions of the specific business areas of their interest.

For example, the NASA Worldwide Reference System (WRS) that is a global notation system for Landsat data allows the users to get some satellite-based predictions in any part of the world by specifying the nominal scenic center labeled PATH and ROW. WRS has proven to be valuable for cataloging, referencing and daily use of images transmitted from Landsat sensors. (NASA, 2019). In this example, it is possible to find similar complex mapping principles with the principles of roadmapping. Roadmapping should also constantly look for the actual path lines based on environmental mapping (in simplicity) like this system. In this way, this innovative attitude enables to solve new more complex problems concerning not only technical or technological aspects but also economic, social, demographic, ethical and other criteria for the strategic decision-making especial in the less developed environment. 


\section{2nd International Conference on Applied Research in ENGINEERING SCIENCE \& TECHNOLOGY}

\section{8-20 October $2019 \quad$ Budapest, Hungary}

Roadmapping should be a systemic process for strategic variant planning especially to foster innovation as a mean to overcome business problems (Wimmer et al., 2007). Roadmapping processes should enable managers to link a strategic vision, mission, functional strategies, investment, capacities, and operational plans with business innovation in a long time. Roadmapping should be a continual but not a "one-shot" process, which helps to coordinate also other business activities such as marketing, $R \& D$, finances, human resources, production, and services together with a business strategy. It can be a part of the main planning process for problematic companies. Roadmapping must consist of a flexible set of methods to support strategic implementation, strategic goals and innovations with or outside of the main industry, including problematic regions, start-ups, SMEs, new regional and sectoral innovation initiatives. It has been shown that its use correlates with the higher performance of a company to better product and technology innovation, and therefore, it is a tool especially needed in a crisis or pre-crisis period (Daim et al., 2018).

\section{Theoretical background and literature review}

According to Möhrle and Isenmann (2017) - strategic innovation management should have a diverse range of tasks: it must be responsible for planning, acquiring, preserving, protecting and utilizing innovation knowledge, processes and capacities and for the market placement of innovations. This focus allows a company to predict a life cycle of innovations together with their often-heterogeneous links, as well as the derivation of measures that serve to maintain or improve the company's competitive position. Understanding the development and problems of innovations also requires an insight into the area of radical innovations. For example, it is well known that the emergence of new technologies is often complex, lengthy and uncertain. Decision-making under these conditions requires the mobilization of different sources and capacities of intelligence to identify both known and unknown trends and risks so that managers can choose appropriate strategies and plans. Zhanga et al. (2016) claim that this competitive so-called innovative intelligence cannot rely on simple trend analysis or extrapolation because breakthrough innovations have little or no past. However, group, transparent and repeatable techniques need to be used to develop and evaluate strategic innovation variants. In high-end businesses, many managers show increased readiness to invest in the digital transformation of their company - currently referred to as Industry $4.0-$ but they are unaware of their current state, the state of Industry 4.0 and the strategic guidance for its implementation. Here, roadmapping, especially for troubled businesses, can also be in great help. (Schumacher et al., 2019) This process is particularly challenging in times of a crisis when managers often only focus on operational issues. Problematic firms are characterized by negative economic results, indebtedness and an inability to repay loans as well as by a need to reduce production capacities and lay off employees. For these businesses in a certain area, it is advisable to make simpler Problematic technology roadmapping or participate in RM, e.g. at the level of an innovative park, an industry, or a region. 


\section{2nd International Conference on Applied Research in ENGINEERING SCIENCE \& TECHNOLOGY}

\section{8-20 October $2019 \quad$ Budapest, Hungary}

The roadmapping methodologies have developed a new integrated approach to strategic planning that combines two perspectives: it focuses on better strategic innovation planning of companies, and public authorities should create better conditions for private companies to implement those innovations. (Vinayavekhin \& Phaal, 2019)

Forecasts and participatory plans should focus on long-term goals of socio-ecological and economic-technological development (which combine a market pull and technology push approach). Based on Vishnevskiya et al. (2016) - this dual approach provides better potential for alternative ways of choosing the most efficient allocation of resources and knowledge. Integrated plans should include different stages of the development of innovation, stages of the existing innovative value chain, including $R \& D$, production, a market entry, services, and market expansions as well as prospective phases, including new technologies, products, and services. The value of "problematic" planning lies in an ability to better respond to new challenges, trends, and risks in the environment and a company, a sector, and a region. Considering future market requirements, stakeholders' requirements, financial options, legislative measures, etc.

Problematic roadmapping applications should support a range of planning activities, but in a simpler pragmatic way:

- Science planning - Science planning should be a multifunctional process that must include requests from various experiments, research teams, disciplines or operational processes. Planning of science should be based on synergetic approaches to prove better coverage of scientific themes derived from core business goals.

- Product planning - The most common kind of roadmapping, often affects the technological RM or relates to the insertion of technology into manufactured products, sometimes including more than one product generation.

- Technology planning - It is one of the most important processes to use technology effectively in an organization. Technology planning processes should help support technology trends and requirements or minimize technology-related problems and avoid wasting money on unnecessary equipment and technology.

- Capability planning - A type of roadmap very similar to product RM but more suited to service-based enterprises (that is the trend now in many areas), focusing on the knowledge insertion into non-material capabilities.

- Integration plans - Where a roadmap focuses on the integration or evolution of an organizational structure in terms of how different processes and capacities are combined to form a new synergic structure.

- Program planning - Focusing on the implementation of a strategy into operational plans and more directly to project planning.

- Process planning - This new type of roadmap supports Knowledge management, focusing on a process area. 


\section{2nd International Conference on Applied Research in ENGINEERING SCIENCE \& TECHNOLOGY}

- Long-range planning - Used to extend the planning time to new event horizons, often performed at the sector, national or global level.

- Strategic planning - This type of roadmapping should include a strategic dimension in terms of supporting the evaluation of changes and innovation in the core business activities resulting in different opportunities and threats at the strategic level.

- Cross-functional problematic analyses - Once roadmapping is successfully used across several operating units, common needs, gaps, and duplicative programs can be identified by looking across roadmaps, etc. (Probert \& Randor, 2003; Geum et al., 2011; Cetindamar et al., 2016)

The main feature of problematic technology roadmapping should be that groups of different stakeholders in a company come together to develop a consensus variant vision for the future of the technological innovation and problems that affected their business. A roadmapping approach in bigger problematic companies should be based on the involvement of suppliers, creditors, investors, main customers, or representatives of the region, etc. (Hussain et al. (2017) A multifunctional attitude, freethinking environment, clear business needs, effective timing, landscape activities, and many other factors influence the right roadmap creation.

At the business, regional and industry levels, problematic technology roadmapping should have several potential uses and resulting benefits. Success depends on how roadmapping concepts and methods can be aligned to support technology innovation or problematic processes in the company, rather than implemented as separate approaches. This is especially important in the crisis period when a company has limited resources, bad-will, and weak opportunities. Roadmapping can support the problematic business processes at different stages, although how it is used may vary. A visual roadmap provides a consistent framework throughout business processes, technology, resources or capacities with the content of the roadmap evolving to ensure that the best current thinking is articulated and communicated. (Phaal, 2006) The basic concept of RM is very flexible, the procedures and methods of this visual variant planning should be tailored to different goals of various institutions that may support technology innovation, the development of business strategies and policies, the allocation of resources, overcoming of business problems, etc. The important contribution of RM should be broader communication in the preparation of a strategic plan across functional and organizational boundaries (Phaal, 2015). The next benefit of RM is that it should provide clear visual information and control to help managers and investors make better strategic decisions. 


\section{2nd International Conference on Applied Research in ENGINEERING SCIENCE \& TECHNOLOGY}

\section{8-20 October 2019

\author{
Budapest, Hungary
}

It must do this by an identifying critical process of the institution and in the environment, new business opportunities or risks that must be improved to meet business performance goals and plans: more competitive and more realistic. Nevertheless, management must identify smart variants to leverage strategic risks and investments through coordinating processes either within a single company or among alliance members (Carayannis et al., 2016). To make the results of this process more realistic, it is necessary to invite business stakeholders to strategic planning.

According to Despeisse et al. (2017) - one of the benefits should be that management understands strategic needs, key technology, and business problems and has access to or is developing the processes to meet these needs or overcome those problems. However, at the industry or regional levels, roadmapping must involve multiple companies, or institutions either as a consortium or as an entire industry. This level of roadmap allows the industry to develop the key underlying technologies and products, rather than redundantly funding the same research. This can result in significant benefits because a certain technology or a product development may be too expensive for a single company to support or take too long to develop, given the limited resources that can be justified. Thus, roadmap prioritizes investments based on drivers and key problems and enables to exploit better future opportunities.

Problematic technology roadmapping should be applied and expanded across organizations of varying sizes, from small businesses to major government policy projects, to achieve effective alignment of strategic goals with major concerns and key technology innovations of the business, industry, or region. (Alcantara \& Martens, 2019) It can also be used as a strategic marketing tool for the selection of what technology represents the key value for a corporation especially during the crisis. A roadmap should explain business needs to strategic members, employees, management, and customers and all stakeholders by allowing them to recognize and participate in events that require a change in direction for the common success. In the main, roadmapping is critical especially when business results are not straightforward.

Properly directing the strategic processes and capabilities of a company is very demanding in a business crisis time, especially when it is caused by the external environment and conditions. According to our research, many times, there is an objective reason within a company. Among the frequent reasons are a lack of market research and not knowing the causes of market problems, a poor financial structure of a company, low technology innovation support, disrespect for employees, suppliers and customers, poor strategic culture, poor communication and awareness, no strategy, strategic management only dealing with operational problems, poor division of authority and responsibility, minor problems are not solved, unethical business practices, poor and dangerous products and inadequate services, etc. 


\title{
2nd International Conference on Applied Research in ENGINEERING SCIENCE \& TECHNOLOGY
}

\section{8-20 October 2019}

\author{
Budapest, Hungary
}

Several authors claim that the form of the roadmap should be tailored to the specific needs of an industry, a region or a company. Problematic roadmaps can be created totally, partly, or together with business partners, depending on the purpose of the roadmap developed and the form of cooperation. Roadmaps can be divided into a taxonomy consisting of science or technology roadmaps, industry or regional roadmaps, product-technology roadmaps, and strategic or strategic roadmaps (Farrukh et al., 2017; Albright \& Kappel, 2003). Roadmaps should take a form of a multi-layered time-based chart that includes different layers of a purpose and knowledge that relate to specific goals, deliveries, and resources (Phaal, 2006 \& 2015). In literature, the basic expression of a roadmap is often used as technology roadmap; it means roadmapping focuses on implementing technology innovation, as is our research focus. The main purpose of the problematic technology roadmapping is to solve the problem by implementing relevant technology innovation and business processes, knowledge and resources.

According to Möhrle \& Isenmann (2017), there are three kinds of roadmaps: Regional, Industry and Corporate/Strategic roadmap. A Roadmap of Region should answer to the questions like: What can we do to improve the economic and social situation in our environment or to change the direction of environmental degradation, not only climate

change, but also resource depletion, energy shortages, and species loss? Can we expect all our efforts to be enough to change our future? What should our environmental goals be? An Industry Roadmap should not describe only how to start from the problematic situation in the industry. It should show how to reach an eligible future and long-term goals. How to better understand what trends and problems our industry has, or can we work together with our industrial partners to improve the situation or can we implement new industrial norms? Strategic/Corporate RM, to distinguish from Regional or Industry roadmaps, is becoming recognized as a tool to achieve critically needed strategic focus, processes and cross-unit integration of technology, product and service programs as these must be integrated and move forward over time.

\section{Research methodology}

This scientific article aims to bring roadmapping issues to 500 problematic companies in the Slovak Republic by presenting specialized professional literature, by statistical and qualitative analysis of these enterprises mainly in Banská Bystrica and Košice regions. This economic research was based on the literary analysis, various empirical studies and statistical vs. qualitative research in 500 problematic companies. The methodology of this research was based on the study of various initiatives on technology analysis, technology innovation management, technology assessment, open technology innovation approaches and participatory innovation in the environment of the less developed regions. Our problematic businesses are mainly SMEs, so it was necessary to modify and simplify our assessment methodology. In the formulation of the methodology, we have considered some similar projects too. For example, the INNO-rural network project (Innovation for Sustainable Rural 


\title{
2nd International Conference on Applied Research in ENGINEERING SCIENCE \& TECHNOLOGY
}

\section{8-20 October 2019}

\author{
Budapest, Hungary
}

Development between Slovenia and Austria) has expanded its strategic innovative concepts by applying them in border regions. This framework has been also tested in the Märkisch-Oderland modeling region (MOL) in Germany. (Schwerdtner et al., 2015) Both approaches bring several positive results for both regions and their institutions. Based on the different concepts of regional and strategic open innovation processes, the assumptions for these processes in the two less developed regions of the SR were monitored through the quantitative statistical and by qualitative consultative studies.

The analysis of problematic companies took place mainly throughout 2018 , with around $90 \%$ of problem firms identified in two regions. The quantitative and qualitative research was carried out in the most problematic regions of the Slovak Republic in the Banská Bystrica and Košice regions. 1 Although there is no clear definition of the term "problematic company", the European Commission defines that a company is problematic when it is unable to stop its

bankruptcy with its financial resources or resources that its owners/shareholders and creditors can provide. It is in a loss that will lead to almost a certain economic demise in the short or long term without external intervention by the state.

Specifically, the business is problematic: In the case of a company which has lost more than half of its capital and more than one-quarter of its capital has been lost in the last 12 months, or in the case of the company in which at least some members have unlimited liability for their debts if they have lost more than half of their capital and more than onequarter of that capital has been lost in the last 12 months, or if it is included in collective insolvency proceedings. Society can be problematic if there are common indications of problematic business. They include: Increase in losses, decrease in turnover, increase in inventories, excess production capacity, decrease in cash flow, increase in lending, increase in economic burden and weakening of net asset value. (EC, 2017) Etc. A problematic company in the context of our research is a company that must dismiss employees for economic reasons in the past 5 years, with at least 2 times negative economic results over the past three years. While 500, such companies were identified in both problem regions of Slovakia (250:250 in both regions). Problem regions were evaluated based on basic economic criteria at first. From the point of view of our research in the field of IA of Slovak industrial enterprises, the Regional Industrial (Innovation) Competitiveness of Individual Slovak Enterprises was significant too. The main indicators within this innovation dimension include, but are not limited to: R\&D spending, researchers' salaries and the number / growth / decline of

$1 \mathrm{BB}$ region (Banská Bystrica region). The region of Banská Bystrica lies in the centre of the country and it borders with Hungary in the south. Metropolis of the region with a rich mining history is the town Banská Bystrica. The population of about 662121.

KK region (Košice region). The region Košice is situated in the southeast of Slovakia. It borders with Hungary and Ukraine in the south and east respectively. The metropolis of the region and the whole eastern Slovakia is the city of Košice - the center of commerce, trades, culture, and education of the whole region. Košice is the second biggest town of Slovakia and as such, it contains numerous cultural and historic monuments. The population of about 770 508. (Slovakia.travel, 2019) 


\title{
2nd International Conference on Applied Research in ENGINEERING SCIENCE \& TECHNOLOGY
}

\section{8-20 October 2019}

\author{
Budapest, Hungary
}

knowledge workers, patent applications and other forms of intellectual property protection, number of scientific publications, Ph.D. study graduates, number of scientific-technical clusters, etc. We have considered all these indicators. The questionnaire survey was conducted in the second half of 2018 and is still ongoing this year. The average response rate of sent questionnaires was around $30 \%$. If the questionnaire had a lower return, it was simplified and sent again. Until now, companies have received about 100 strategic, manufacturing, financial, personnel, and especially innovative management questions. Identified findings have been consulted with business managers, production and innovation managers. Thus, the statistical results were completed by expert consultations in 2018-2019.

\section{Research results and proposals}

The first result includes several statistical information and scientific findings. The second outcome of our study is to propose a simple model approach of RM for problematic companies based on the analyses made. Based on these results, it can be concluded that these problematic companies are mainly micro-companies with up to 10 employees (mostly Ltd.), mainly in the construction, engineering/automotive, rubber and plastic industries. These companies are dominated by piece and series production. The smaller companies usually offer an assortment within one industry, the larger companies usually offer assortment across multiple industries. Customers usually demand high-quality products and services. A simple functional organizational structure prevails in terms of the business organization. In terms of business rivalry, about $25 \%$ of companies reported unfair business practices and competition fraud. However, more than $30 \%$ of the companies reported some B2B collaboration as a prerequisite for open innovation cooperation. For these companies, competition in the EU markets is the greatest. While more than, 33\% of these companies reported no support from both EU and national authorities in terms of innovation activities. However, more than 20\% of these companies reported a strong impact of technological progress on business activities. While, in the Banská Bystrica region, technological progress mainly means new opportunities for a company. In addition, in the Košice region, this progress does not usually affect business.

Typically, companies usually report weak opportunities to participate in knowledge centres and research parks in the region. In terms of long-term planning and roadmapping, companies usually state that there is informal innovation culture and a non-systematic approach to business innovation planning. Roadmapping processes have only been applied in a minimum number of larger businesses (TR $\geq 500000 €$ ). About a third of small businesses do not have an innovation strategy but they have a plan. In terms of market research, these companies usually carry out random surveys as needed. Systemic technology radar processes have not been identified. In smaller companies, an owner of the business, management of the company and R\&D management are usually involved in innovation planning. The focus of roadmapping in larger companies is largely on technological innovation and product innovation. Roadmapping goals usually depend on the innovation plan, economic outcomes and owner's requirements. A roadmapping plan is usually done for 1 year as well. About $30 \%$ of small businesses say that the innovation plan is only for one year. The link between risk management and innovation processes has not been identified in strategic planning. An 


\title{
2nd International Conference on Applied Research in \\ ENGINEERING SCIENCE \& TECHNOLOGY
}

\section{8-20 October 2019}

\author{
Budapest, Hungary
}

innovation strategy is often just a formal document. In terms of technology innovation activities, employees are trained as needed in more than $40 \%$ of businesses. Technology innovations are usually funded from profits in more than $73 \%$ of businesses, followed by bank loans and owner deposits. Technology innovation predominantly affects the growth of economic results in small businesses and the improvement of the goodwill and the market share of larger businesses. As a major barrier to improving technology innovation, most companies consider low customer interest in changing products and services. Smaller companies usually lack funding for technology innovation. Employees are usually involved in technology innovation, but that is not their job. And many businesses report that employees are usually not interested in technology innovation.

The average loss of smaller firms (usually up to 10 employees) in the Banská Bystrica region was $-16547 €(2016) ;-13042 €(2017) ;-12945 €(2018)$. For larger companies, the average loss was $-274712 €(2016) ;-182406 €(2017) ;-163475 €(2018)$. This means that the average loss rates declined over time in both types of companies. The average loss of smaller companies in the Košice region was -16 380 (2016); -8 $923 €(2017) ;-22191 €$ (2018). For larger companies, the average loss was -445 $549 €$ (2016); -1 $052849 €$ (2017); $338456 €(2018)$. The variability and the amount of negative economic results were higher in the Košice region. This means that the situation in support of strategic technology innovation planning and technology innovation support is even worse than in the BB region. (Tab. 1.) 


\section{2nd International Conference on Applied Research in}

\section{ENGINEERING SCIENCE \& TECHNOLOGY}

\section{8-20 October 2019}

\section{Budapest, Hungary}

Table 1: Highest evaluation results of partial aspects of technology innovation and roadmapping in 500 problematic businesses of the $S R$.

\begin{tabular}{|c|c|c|c|c|c|}
\hline & $\begin{array}{l}\text { BB region, } \\
\text { micro- } \\
\text { companies } \\
(\mathrm{TR} 2<500 \\
000 €)\end{array}$ & $\begin{array}{l}\text { BB region, } \\
\text { SMEs } \\
(\mathrm{TR} \geq 500 \\
000 €)\end{array}$ & $\begin{array}{l}\text { KK region } \\
\text { micro- } \\
\text { companies } \\
(\mathrm{TR}<500 \\
000 €)\end{array}$ & $\begin{array}{l}\text { KK region } \\
\text { SMEs } \\
(T R \geq 500 \\
000 €)\end{array}$ \\
\hline & & \multicolumn{4}{|c|}{$\%$} \\
\hline Type of business & Ltd. & 73,3 & 100 & 50 & 66,7 \\
\hline \multirow{2}{*}{ Type of production } & $\begin{array}{l}\text { Piece } \\
\text { production }\end{array}$ & 50 & - & 50 & 66,7 \\
\hline & $\begin{array}{l}\text { Serial } \\
\text { production }\end{array}$ & 21,4 & 100 & 12,5 & 33,3 \\
\hline \multirow[b]{2}{*}{ Type of assortment } & $\begin{array}{l}\text { Wide within } \\
1 \text { industry }\end{array}$ & 26,7 & 100 & 62,5 & 66,7 \\
\hline & $\begin{array}{l}\text { Wide across } \\
\text { multiple } \\
\text { industries }\end{array}$ & 33,3 & - & 12,5 & - \\
\hline $\begin{array}{l}\text { Type of organizational } \\
\text { structure }\end{array}$ & $\begin{array}{l}\text { Simple } \\
\text { functional IP }\end{array}$ & 40 & 100 & 50 & 66,7 \\
\hline \multirow[t]{2}{*}{ Market share } & $\begin{array}{l}\text { Less than } \\
10 \%\end{array}$ & 53,3 & - & 62,5 & - \\
\hline & Over $10 \%$ & 6,7 & 100 & 12,5 & 66,7 \\
\hline \multirow{2}{*}{$\begin{array}{l}\text { Possibility of company } \\
\text { involvement in knowledge } \\
\text { centers and research parks }\end{array}$} & Weak & 46,7 & - & 37,5 & 100 \\
\hline & No & 26,7 & - & 37,5 & - \\
\hline Quality of market research & $\begin{array}{l}\text { Irregular, } \\
\text { random }\end{array}$ & 40 & 100 & 50 & 33,3 \\
\hline \multirow{3}{*}{$\begin{array}{l}\text { Responsibility for } \\
\text { technology innovation }\end{array}$} & Owner & 73,3 & - & 50 & 33,3 \\
\hline & $\begin{array}{l}\text { Strategic } \\
\text { management }\end{array}$ & 46,7 & 50 & 25 & 66,7 \\
\hline & $\begin{array}{l}\text { Research and } \\
\text { innovation } \\
\text { management }\end{array}$ & 6,7 & 50 & - & - \\
\hline $\begin{array}{l}\text { Length of technology } \\
\text { innovation cycle }\end{array}$ & $\begin{array}{l}\text { More than } 3 \\
\text { years }\end{array}$ & 21,4 & 100 & 50 & 33,3 \\
\hline Innovation training & $\begin{array}{l}\text { Training as } \\
\text { needed }\end{array}$ & 46,7 & 100 & 42,9 & 33,3 \\
\hline $\begin{array}{l}\text { Financing technology } \\
\text { innovation }\end{array}$ & Profit & 73,3 & 100 & 75 & 100 \\
\hline
\end{tabular}

${ }^{2}$ Annual total revenues 


\section{2nd International Conference on Applied Research in ENGINEERING SCIENCE \& TECHNOLOGY}

\section{8-20 October 2019}

Source: (own data)

\section{Budapest, Hungary}

\subsection{Roadmapping Participants Proposal for Problematic Companies}

Roadmapping should bring together a right team of experts to develop a framework for organizing and presenting the critical planning information to make the appropriate investment decisions and to leverage the risks. Strategic or regional/industry roadmapping require a certain set of information, knowledge, and skills. Roadmapping processes can also be organized by governmental, regional or sectoral institutions, which can also have specific resources from international organizations. Such support is often lacking in problematic regions. At the business level, roadmaps should be created by senior management and by main investors, suppliers or customers in the first place. Management is usually responsible for updating roadmaps. (Vishnevskiy et al., 2016) Generally, a corporate RM process should put together also the stakeholders from different functions of the organization. (Gershman et al., 2016) There are examples where hundreds of scientists, engineers, economists, etc. - work on these planning processes in the most successful companies. But, not only the right creation of a roadmapping team is important, but also support from the company is vital regarding capacities, a time frame, and budget investments. This team should be formed including representatives from $\mathrm{R} \& \mathrm{D}$, technology management personnel, members of business development, representatives of finance, and core staff members from different business functions. On the other hand, a roadmapping process can start with a smaller roadmapping team with marketing, product management, R\&D and engineering participates. In addition, after that, an appointed coordinator can gradually complete the team with different employees and external stakeholders. The team should have both commercial and technical perspectives, such as research, development, manufacturing, marketing, and finance (Phaal, 2015).

The core participants or consultants must know the principles of roadmapping. This includes also how to identify needs, problems, and strategic drivers. Some participants must also have knowledge of the area being roadmapped. However, while these skills are important, they are not enough. Equally important are the interpersonal and group process skills. Therefore, a roadmapping project requires a roadmapping consultant or facilitator who has both types of skills (roadmapping and interpersonal) or a well-integrated team that has both types of skills. Generally, a roadmapping process should include the main stakeholders from different levels and functions of the organization and the business environment, illustrated in Tab. 2. 


\section{2nd International Conference on Applied Research in \\ ENGINEERING SCIENCE \& TECHNOLOGY}

\section{8-20 October 2019 \\ Budapest, Hungary}

Table 2: Importance of participants in Problematic roadmapping process.

\begin{tabular}{|c|c|c|c|c|}
\hline & $\begin{array}{l}\text { Strategic } \\
\text { roadmap }\end{array}$ & $\begin{array}{l}\text { Science } \\
\text { roadmap }\end{array}$ & $\begin{array}{l}\text { Technology } \\
\text { roadmap }\end{array}$ & $\begin{array}{l}\text { Product } \\
\text { roadmap }\end{array}$ \\
\hline Senior Management & $\mathrm{xxx}^{3}$ & $\mathrm{xx}$ & $\mathrm{x}$ & $\mathrm{x}$ \\
\hline Main shareholders & $\mathrm{xxx}$ & $\mathrm{X}$ & $\mathrm{x}$ & $\mathrm{xx}$ \\
\hline Representatives of R\&D & $\mathrm{x}$ & XXX & $\mathrm{XX}$ & $x x$ \\
\hline Technology Management & $\mathrm{x}$ & $\mathrm{xx}$ & $\mathrm{xxx}$ & $x x$ \\
\hline Product Management & $\mathrm{x}$ & $\mathrm{XX}$ & $\mathrm{XX}$ & XXX \\
\hline Marketing & XXX & $\mathrm{x}$ & $\mathrm{x}$ & $\mathrm{xxx}$ \\
\hline $\begin{array}{l}\text { Representatives of } \\
\text { Finance }\end{array}$ & $\mathrm{xxx}$ & $\mathrm{xx}$ & $\mathrm{xx}$ & $\mathrm{xx}$ \\
\hline Sales Partners & - & - & - & $\mathrm{x}$ \\
\hline $\begin{array}{l}\text { Representatives of } \\
\text { Engineering }\end{array}$ & $\mathrm{x}$ & $\mathrm{xx}$ & $\mathrm{xxx}$ & $\mathrm{xx}$ \\
\hline $\begin{array}{l}\text { Representatives of } \\
\text { Manufacturing }\end{array}$ & $\mathrm{x}$ & $\mathrm{x}$ & $\mathrm{xx}$ & $\mathrm{XxX}$ \\
\hline Representatives of & - & $\mathrm{x}$ & $\mathrm{xx}$ & $\mathrm{xx}$ \\
\hline Representatives of PR & $\mathrm{x}$ & - & - & $\mathrm{x}$ \\
\hline $\begin{array}{l}\text { Human Resources } \\
\text { Management }\end{array}$ & $\mathrm{XX}$ & $\mathrm{x}$ & $\mathrm{xx}$ & $\mathrm{xx}$ \\
\hline Representatives of Quality & $\mathrm{x}$ & $x x$ & XXX & XXX \\
\hline
\end{tabular}

Source: (own data)

As can be seen, Problematic foresight should be the matter of Strategic management, main shareholders and Lean management, especially from the Finance department, HRM, PR, Product Management or Marketing. Therefore, a cross-functional team must be established. To prepare a RM plan is not the only purpose of the RM process. Others are to enhance crossfunctional communication within the company. Joint memberships can affect the process too. This is because then all the participants are selected, and agreements are made concerning the roadmapping process. At this point, all the participants, responsibilities and authorities should be clearly defined. It should be decided, who can make the decisions eventually when consensus cannot be reached between team members. When the roadmap was created in joint memberships, then the members had to have a mutual understanding of and deeper insights into the process.

\footnotetext{
3 The numbers of $\mathrm{x}$-symbols represent the importance of participation.
} 


\section{2nd International Conference on Applied Research in ENGINEERING SCIENCE \& TECHNOLOGY}

\section{8-20 October 2019}

\section{Conclusion}

At the business, regional and industry levels, problematic technology roadmapping should have several potential uses and resulting benefits. Success depends on how roadmapping concepts and methods can be aligned to support technology innovation and problematic processes in a company, rather than implemented as separate approaches. This is especially important in the less developed environment when a company has limited resources, bad-will, and weak opportunities. Roadmapping can support the problematic business processes at different stages, although how it is used may vary.

Based on our results, it can be concluded that the problematic companies in two problematic regions of Slovakia are mainly micro-companies with up to 10 employees (mostly Ltd.), mainly in the construction, engineering/automotive, rubber and plastic industries. Bigger companies are better able to overcome crises. These problematic companies are dominated by piece and series production. Mass production companies are also less prone to crises. In terms of long-term planning and roadmapping, companies usually state that there are an informal innovation culture and a non-systematic approach to business innovation planning. Roadmapping processes have only been applied in a minimum number (up to 3\%) of larger businesses (TR $\geq 500000 €$ ). About a third of small businesses do not have an innovation strategy but they have a plan.

This type of economic research is important because most of the roadmapping researches have been done only from the perspective of successful companies. However, the research intention was not to examine which statistical results represent the "best value" for problematic companies. Under these circumstances, the "best" may not be relevant to the less developed and crisis environment. There was some lack of interest in strategic and innovative issues by these problematic companies, because of the need to solve current daily issues. Roadmapping in the context of problematic companies can be considered as one of the most important parts of strategic management in terms of planned out-of-crisis operations. Problematic technology roadmapping can be considered a specific tool for addressing troubled strategic times also in the context of economic crises. There are three important areas for the most important implications of this study for road mapping and strategic innovation planning theory. The first area is the interconnection of crisis management and innovation management, especially as regards the introduction of technology innovations in times of crisis. Who should be responsible for systemic technology innovation if the company has operational problems? According to our study, it is usually top management, which often performs this process inadequately due to the company's daily problems. The second implication is financial security for innovations unless the company can pay its liabilities or pay employees. Usually, it is unable to obtain a bank loan or a business loan. The implication for theory is a solution through a combination of financial instruments, or entry into an entrepreneurial alliance that will allow an enterprise to raise funds for technology innovation activities. 


\section{2nd International Conference on Applied Research in ENGINEERING SCIENCE \& TECHNOLOGY}

The third implication for theory is the issue of motivating and stimulating employees in times of crisis. Many employees have lower incomes during this period, corporate culture is deteriorating in the company, people can come into conflicts or leaking expertise. Ordinary incentives and stimulus models may not be effective in supporting the company's innovation activities in times of crisis, it is essential to tie innovation to concrete benefits for innovators. According to our analysis, the main drawback of systemic support for innovative activities of problematic companies is the lack of motivation and incentives for employees, which weakens the company's innovation and market competitiveness and the company gets even more into a crisis.

The non-systemic approach of many problematic companies, also in terms of market surveys, employee engagement in planning and technology innovation processes, technology innovation support only at times of good economic results and others can be included among the key risks in the problematic environment. Conversely, systemic risk and market opportunities analyses, technology innovation radar, mobilization of own capacities, knowledge, innovation support, long-term innovation planning even in times of crisis can mean some ways to overcome these crises and thus survive in the time of crises. However, this depends on the approach of each company.

\section{Acknowledgment}

This research was carried out within the framework of the VEGA project (1/0235/17): Systemic identification of more comprehensive preconditions to support industrial technology innovation and employment in less developed regions of the SR.

\section{References:}

[1] Albright, R. E. and Kappel, T. A. (2003). Roadmapping in the corporation, ResearchTechnology Management, vol. 46, no. 2, pp. 31-40.

[2] Alcantara, D. P. and Martens, M. L. (2019). Technology Roadmapping (TRM): a systematic review of the literature focusing on models, Technological Forecasting and Social Change, vol. 138, January, pp. 127-138.

[3] Carayannis, E., Grebeniuk, A. and Meissner, D. (2016). Smart roadmapping for STI policy, Technological Forecasting and Social Change, vol. 110, September, pp. 109-116.

[4] Cetindamar, D., Phaal, R. and Probert, D. (2016). Technology management: activities and tools, $1^{\text {st }}$ ed. Palgrave, London, UK.

[5] Daim, T. U., Yoon, B.-S., Lindenberg, J., Grizzi, R., Estep, J. and Oliver, T. (2018). Strategic roadmapping of robotics technologies for the power industry: A multicriteria technology assessment, Technological Forecasting and Social Change, vol. 131, June, pp. 49-66. 


\section{2nd International Conference on Applied Research in}

\section{ENGINEERING SCIENCE \& TECHNOLOGY}

\section{8-20 October 2019}

\section{Budapest, Hungary}

[6] Despeisse, M., Yang, M., Evans, S., Ford, S. and Minshall, T. (2017). Sustainable Value Roadmapping Framework for Additive Manufacturing, Procedia CIRP, vol. 61, pp. 594 599.

[7] Duckles, J. M. and Coyle E. J. (2005). Purdue's Center for Technology Roadmapping: a resource for research and education in technology roadmapping. Proceedings of the IEEE International Engineering Management Conference, Cambridge, UK.

[8] EC (2017). Directive (EU) 2017/1132. [online]. (accessed 20 January 2019). Available: $<$ https://eur-lex.europa.eu/legal-content/EN/ALL/?uri=celex\%3A32017L1132>

[9] Farrukh, C., Athanassopoulou, N., and Phaal, R. (2017). Topic Roadmapping and Performance Dimensions. Centre for Technology Management working paper series. [online]. (accessed 1 February 2019). 〈https://doi.org/10.17863/CAM.13941>.

[10] Gerdsri, N. (2016) Strategic Planning: An Analytical Approach to Building a Technology Development Envelope (TDE) for Roadmapping of Emerging Technologies, In: Daim T. (eds) Hierarchical Decision Modeling. Innovation, Technology, and Knowledge Management. Springer, Cham.

[11] Gershman, M., Bredikhin, S. and Vishnevskiya, K. (2016). The role of corporate foresight and technology roadmapping in companies' innovation development: The case of Russian state-owned enterprises, Technological Forecasting and Social Change, vol. 110, September, pp. 187-195.

[12] Geum, Y., Kang, D., Lee, S. and Park, Y. (2011). The customisation framework for roadmapping product-service integration, Service Business, vol. 5, no. 3, pp. 213-236.

[13]Hussain, M., Tapinos, E. and Knight, L. (2017). Scenario-driven roadmapping for technology foresight, Technological Forecasting and Social Change, vol. 124, November, pp. 160-177.

[14]Möhrle, M. G. and Isenmann, R. (2017). Grundlagen des Technologie-Roadmapping, VDI-Buch, Chapter 1, Technologie-Roadmapping, ed. Springer, Berlin/Heidelberg, Germany.

[15]Phaal, R., Farrukh, C. J. P. and Probert, D. R. (2001). Technology management process assessment: A case study, International Journal of Operations \& Production Management, vol. 21, pp. 1116-1132.

[16]Phaal, R., Farrukh, C. J. P. and Probert, D. R. (2004). A framework for supporting the management of technological knowledge, International Journal of Technology Management, vol. 27, no. 1, pp. 1-15.

[17]Phaal, R. (2006). Technology Roadmapping. IET Management Key. ed. University of Cambridge, UK. 


\section{2nd International Conference on Applied Research in \\ ENGINEERING SCIENCE \& TECHNOLOGY}

\section{8-20 October 2019}

\section{Budapest, Hungary}

[18]Phaal, R. (2015). Roadmapping for strategy and innovation. Proceedings of the IEE Seminar on Justifying and Selecting Innovation Projects, ed. IET, (Ref. No. 2015/11360).

[19] Probert, R. and Randor, M. (2003). Frontier experiences from industry-academia consortia: strategic roadmappers create value with product and technology roadmaps, IEEE Engineering Management Review, vol. 46, no. 3, pp. 28-48.

[20] Schwerdtner, W., Siebert, R., Busse, M. and Freisinger, U. B. (2015). Regional Open Innovation Roadmapping: A New Framework for Innovation-Based Regional Development, Sustainability, vol. 7, pp. 2301-2321.

[21] Simonse, L. W. L., Hultink, E. J. and Buijs, J. A. (2014). Innovation Roadmapping: Building Concepts from Practitioners' Insights, Product Innovation Management, vol. 32, no. 6, pp. 904-924.

[22] Slovakia.travel (2019). Regional division. [online]. (accessed 7 February 2019). <http://slovakia.travel/en/about-slovakia/regional-division>.

[23] Schumacher, A., Nemeth, T. and Sihn, W. (2019). Roadmapping towards industrial digitalization based on an Industry 4.0 maturity model for manufacturing enterprises, Procedia CIRP, vol. 79, pp. 409-414.

[24] Vatananan, R. S. and Gerdsri, N. (2012). The Current state of technology roadmapping (TRM) research and practice, International Journal of Innovation and Technology Management, vol. 9, no. 4.

[25] Vinayavekhin, S. and Phaal, R. (2019). Synchronization in strategic planning: A roadmapping framework, International Journal of Innovation and Technology Management, March.

[26] Vishnevskiya, K., Karasev, O. and Meissner, D. (2016). Integrated roadmaps for strategic management and planning, Technological Forecasting and Social Change, vol. 110, September, pp. 153-166.

[27]Wimmer, M. A., Codagnone C. and Xiaofeng Ma. (2007). Developing an E-Government Research Roadmap - Method and Example from E-GovRTD2020. Lecture Notes in Computer Science, ed. Springer, Berlin/Heidelberg, Germany.

[28]Zhanga, Y., Robinson, D. K. R., Porter, A. L., Zhu, D., Zhan, G. and Lu, J. (2016). Technology roadmapping for competitive technical intelligence, Technological Forecasting and Social Change, vol. 110, September, pp. 175-186. 